\title{
Probability of extraprostatic disease according to the percentage of positive biopsy cores in clinically localized prostate cancer
}

\author{
Thiago N. Valette ${ }^{1}$, Alberto A. Antunes ${ }^{1}$, Kátia Moreira Leite ${ }^{1}$, Miguel Srougi ${ }^{1}$ \\ ${ }^{1}$ Divisão de Urologia da Universidade de São Paulo Faculdade de Medicina de São Paulo, Brasil
}

\section{ABSTRACT}

Objective: Prediction of extraprostatic disease in clinically localized prostate cancer is relevant for treatment planning of the disease. The purpose of this study was to explore the usefulness of the percentage of positive biopsy cores to predict the chance of extraprostatic cancer.

Materials and Methods: We evaluated 1787 patients with localized prostate cancer submitted to radical prostatectomy. The percentage of positive cores in prostate biopsy was correlated with the pathologic outcome of the surgical specimen. In the final analysis, a correlation was made between categorical ranges of positive cores (10\% intervals) and the risk of extraprostatic extension and/or bladder neck invasion, seminal vesicles involvement or metastasis to iliac lymph nodes. Student's t test was used for statistical analysis.

Results: For each 10\% of positive cores we observed a progressive higher prevalence of extraprostatic disease. The risk of cancer beyond the prostate capsule for $<10 \%$ positive biopsy cores was 7.4\% and it increased to 76.2\% at the category $90-100 \%$ positive cores. In patients with Gleason grade 4 or 5 , the risk of extraprostatic cancer prostate was higher than in those without any component 4 or 5.

Conclusion: The percentage of positive cores in prostate biopsy can predict the risk of cancer outside the prostate. Our study shows that the percentage of positive prostate biopsy fragments helps predict the chance of extraprostatic cancer and may have a relevant role in the patient's management.

\section{ARTICLE INFO}

\section{Key words:}

Prostatic Neoplasms;

Prostatectomy

Int Braz J Urol. 2015; 41: 449-54

Submitted for publication:

October 29, 2014

Accepted after revision:

December 01, 2014

\section{INTRODUCTION}

Prostate cancer is the second most common cancer in humans, being surpassed only by the skin tumors. In 2008, the disease was responsible for 14\% (903.500) of total cancer cases around the World and for 6\% (258.400) of all cancer deaths in men (1).

In patients with disease confined to the prostate radical prostatectomy is followed by a significant reduction in mortality and in the risk of metastases as compared to active surveillance in intermediate and high risk prostate cancer (2, 3). On the other hand, when the disease is locally advanced, the survival and prognosis of the patient are less favorable when compared with figures seen in disease confined to the prostate.

Currently, serum PSA, clinical stage and Gleason biopsy score are the main predictor variables for pathologic outcome after radical surgery 
(4). Some recent studies have suggested that quantifying the volume of the cancer or the number of positive biopsy cores can predict the presence of metastases, tumor recurrence and mortality of the disease (5-9).

The objective of our study was to determine whether the percentage of positive cores on prostate biopsy is useful to predict the probability of the presence of the tumor outside the prostate, which would have obvious therapeutic and prognostic implications.

\section{MATERIALS AND METHODS}

This was a retrospective study analyzing 1787 patients bearing clinical localized prostate adenocarcinoma submitted to radical prostatectomy from 1998 to 2011 and who had not received any previous treatment.

All cases were diagnosed by elevated serum PSA or palpable nodule at digital rectal examination and were diagnosed by ultrasound guided biopsy, that involved the removal of 8 to 22 cores (mean 12.5, median 12.0) of each patient. All radical prostatectomies were performed by the same surgeon (MS) and all the surgical specimens were examined by the same pathologist (KRML). In this review surgical complications were not accessed.

The clinical data collected from patients were age, biopsy Gleason score, preoperative PSA levels, the number of positive biopsy cores and the total number of biopsy samples collected (Table-1), that allowed to establish the percentage

Table 1 - Clinical data of patients.

\begin{tabular}{lc}
\hline $\mathrm{N}=1787$ & $\begin{array}{c}\text { Mean } \\
\text { (standard deviation) }\end{array}$ \\
\hline Age & $61.43(7.93)$ \\
Gleason score & $6(1.19)$ \\
PSA value & $7.37(5.59)$ \\
Total number of biopsy samples collected & $12.58(4.70)$ \\
Number of positive biopsy cores & $3.94(2.79)$ \\
Percentage of positive biopsy cores & $34.0 \%$ \\
Percentage of extraprostatic disease & $24.5 \%$ \\
Percentage of lymph nodes involvement & $9.0 \%$ \\
Percentage of seminal vesicle involvement & $1.2 \%$ \\
\hline
\end{tabular}

of positive biopsy cores. This last parameter was then correlated with the presence of extraprostatic disease, seminal vesicle and/or lymph nodes involvement in the final pathologic analysis of surgical specimens. Biopsy Gleason scores were graded according to the International Society of Urological Pathology (ISUP) (10). The specimens were processed through the whole-mount method. The extraprostatic disease was defined as the invasion of adipose tissue and/or of the periprostatic neurovascular plexus.

Patients were categorized by the percentage of positive cores in groups of ten percent. For each category, the chance of the disease extended outside the prostate $\left(\mathrm{pT}_{3} \mathrm{~N}_{0}\right.$ or $\left.\mathrm{N}_{1}\right)$ was noticed. Subsequently, we analyzed the patients in two subgroups, one carrying grade 4 or 5 component in the biopsy Gleason score and other without grade 4 or 5 component. In each subgroup the chance of extension of the disease outside the prostate was calculated for each category of 10\% positive cores.

Summary statistics were used (mean, standard deviation, maximum and minimum) and comparison between the percentage of positive cores and extraprostatic disease was made by using Student's t test (11). The tests were performed with a significance level of 5\%.

We also created a formula to predict the chance of finding tumor outside the prostate based on the percentage of positive cores using a logistic regression model (12).

\section{RESULTS}

The results are shown in Figures 1 to 3 . As can be noted, for each 10\% of positive cores a progressive increase in the risk of extraprostatic disease was observed (Figure-1). This finding was observed either in cases without grades 4 or 5 Gleason component in the biopsy (Figure-2) as well as in those with these grades present (Figure-3). Clearly, the risk of extraprostatic disease for the same percentage of positive cores was higher

$$
P=\frac{e(-2,21204+3,17286 \times \text { percentage of positive cores })}{1+e(-2,21204+3,17286 \times \text { percentage of positive cores })}
$$


Figure 1 - Chance of extraprostatic disease according to the percentage of positive biopsy cores for all patients.

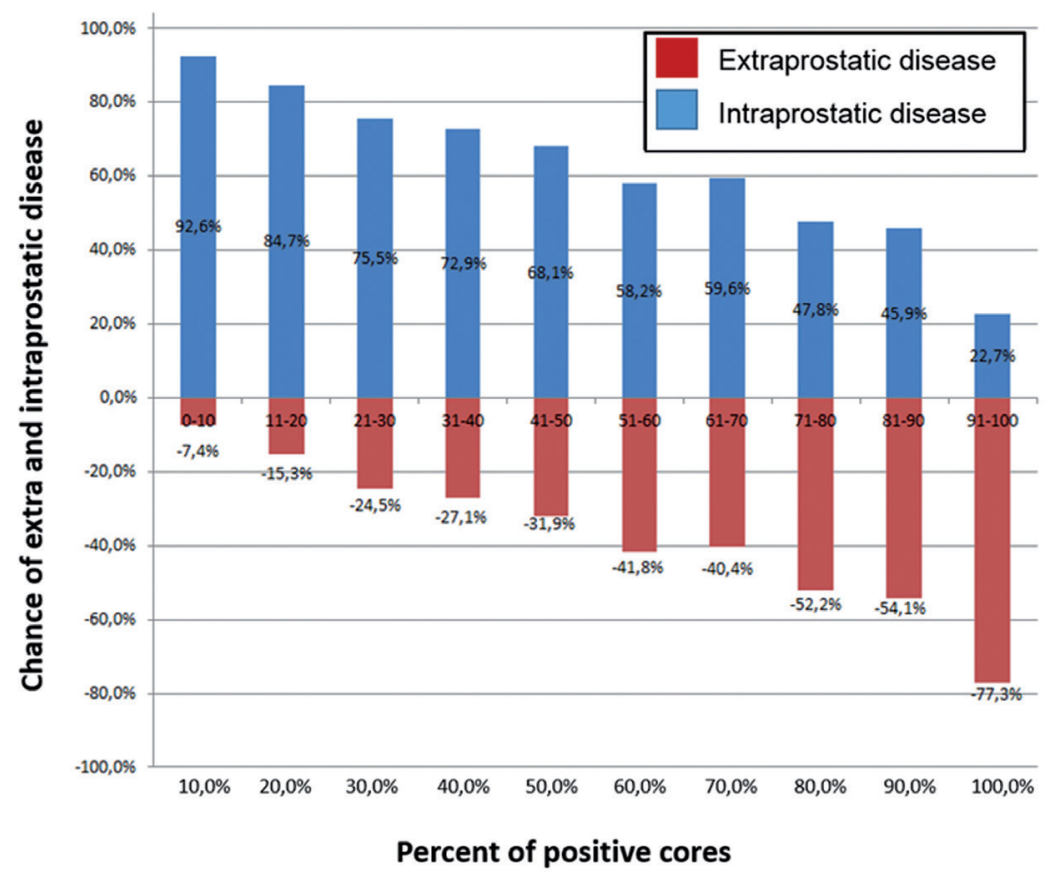

Figure 2 - Chance of extraprostatic disease in patients without grade 4 or 5 component in the biopsy Gleason score.

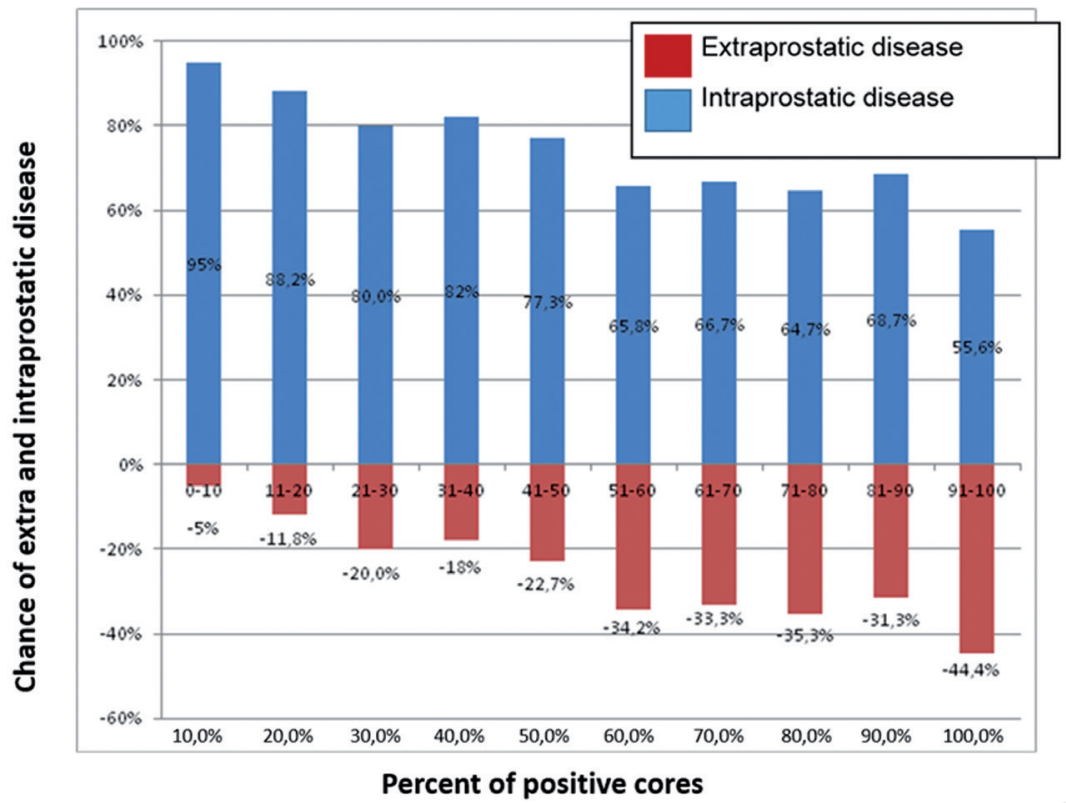

in cases with grades 4 or 5 present in the biopsy (figures 2 and 3).

As can be seen in the Table- 2 the mean percentage of positive cores is statistically higher in cases with tumor outside the prostate $\left(\mathrm{pT}_{3}\right.$ or $\left.\mathrm{N}_{1}\right)$ than in cases with tumor confined to prostate $\left(\mathrm{pT}_{2}\right)$ $(\mathrm{p}<0.001)$.

The formula found for predicting the probability of the tumor extended outside the prostate to all patients according to percentage of positive 
Figure 3 - Chance of extraprostatic disease in patients with grade 4 or 5 in the biopsy Gleason score.

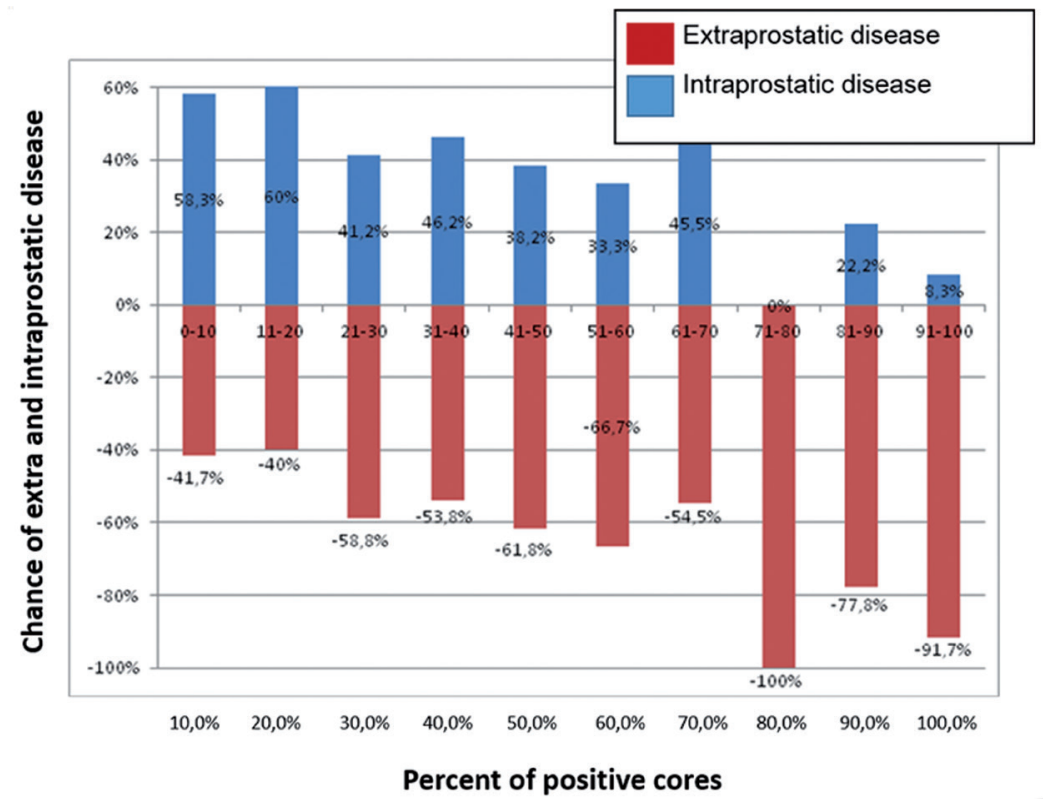

Table 2 - Correlation between the percentage of positive biopsy cores and the pathologic stage in patients with and without grade 4 or 5 component in biopsy Gleason escore.

\begin{tabular}{|c|c|c|c|c|}
\hline Group & Pathologic stage & $\mathrm{N}^{0}$ Patients & Mean positive cores (\%) & P Value \\
\hline With & $\mathrm{pT}_{2}$ & 890 & 26.6 & $p<0.001$ \\
\hline GL 4 or 5 & $\left\{\mathrm{pT}_{3}\right.$ or $\mathrm{N}_{1}$ & 177 & 38.2 & \\
\hline Without & $\mathrm{pT}_{2}$ & 429 & 19.4 & $P<0.001$ \\
\hline GL 4 or 5 & $\left\{\mathrm{pT}_{3}\right.$ or $\mathrm{N}_{1}$ & 283 & 25.4 & \\
\hline \multirow[t]{2}{*}{ All Patients } & $\left\{\quad \mathrm{pT}_{2}\right.$ & 1324 & 19.4 & $p<0.001$ \\
\hline & I $\quad \mathrm{pT}_{3}$ or $\mathrm{N}_{1}$ & 463 & 24.6 & \\
\hline
\end{tabular}

biopsy cores is as follows bellow. The number $e$ is an important mathematical constant that is the base of the natural logarithm. It is approximately equal to 2.71828 .

\section{DISCUSSION}

According to the present study, the higher the percentage of positive biopsy cores, the higher the chance to find tumor outside of the prostate and this finding is more prominent when biopsies show grade 4 or 5 component in the Gleason score.
Our results are reinforced by the large number of patients included in the study. In addition, all radical prostatectomies and pathologic analysis were performed by the same surgeon and pathologist allowing a better standardization of our data. However there were some limitations in the present study. In some patients a smaller number of total cores was retrieved, but the total sample was always greater than six. It would be more accurate if all biopsies involved a large number of cores, since the extended biopsies are superior to the outdated sextant technique for detection of prostate cancer (13- 
17). Moreover, the biopsies were not performed by the same physician. Additionally, the formula which was described is not simple for routine use in the routine clinical practice. However it can be used for calculating the probability of extraprostatic disease in a future nomogram.

Leite et al. in 2003 demonstrated the importance of determining the volume of the tumor when used in conjunction with the Gleason histological score, but the overall extent of tumor in the positive cores appeared to be the most informative of all parameters studied (18). In 2005, Antunes et al. demonstrated the usefulness of the percentage of positive cores to determine the recurrence of prostate cancer (7). Later, this group observed that the percentage of positive cores is the best method among the different parameters to determine the tumor volume (6).

The percentage of positive cores has been associated with tumor pathological features, biochemical recurrence, distant metastases, overall survival, capacity to determine extraprostatic extension of tumor and lymph node invasion, but most of these studies have some shortcomings such as small sample size and short term patients' follow-up (1118). Consequently, the use of serum PSA, clinical stage and Gleason score to predict the probability of the tumor extending outside the prostate still persist as useful prognostic tools up to the present days (4).

We hope that with this study the percentage of positive cores can be incorporated to the clinical practice to aid in the proper staging of disease, improving the therapeutic planning and the outcome of patients with clinically localized prostate cancer. As is well known, the prognosis of patients with disease outside the prostate is gloomy (19) and justifies changes in treatment strategy to improve patients' outcome.

In conclusion, the results of the present study suggest that the inclusion of the percentage of positive biopsy cores in the construction of preoperative nomograms allows a better staging of the disease in patients with apparently localized prostate cancer and can help the treatment strategy decision.

\section{CONFLICT OF INTEREST}

None declared.

\section{REFERENCES}

1. Jemal A, Bray F, Center MM, Ferlay J, Ward E, Forman D. Global cancer statistics. CA Cancer J Clin. 2011;61:69-90.

2. Vickers A, Bennette C, Steineck G, Adami HO, Johansson JE, Bill-Axelson A, et al. Individualized estimation of the benefit of radical prostatectomy from the Scandinavian Prostate Cancer Group randomized trial. Eur Urol. 2012;62:204-9.

3. Bill-Axelson A, Holmberg L, Filén F, Ruutu M, Garmo H, Busch C, et al. Scandinavian Prostate Cancer Group Study Number 4. Radical prostatectomy versus watchful waiting in localized prostate cancer: the Scandinavian prostate cancer group-4 randomized trial. J Natl Cancer Inst. 2008 Aug 20;100:1144-54.

4. Partin AW, Kattan MW, Subong EN, Walsh PC, Wojno KJ, Oesterling JE,et al. Combination of prostate-specific antigen, clinical stage, and Gleason score to predict pathological stage of localized prostate cancer. A multi-institutional update. JAMA. 1997;277:1445-51. Erratum in: JAM 1997;278:118.

5. Heidenreich A, Pfister D, Thüer D, Brehmer B. Percentage of positive biopsies predicts lymph node involvement in men with low-risk prostate cancer undergoing radical prostatectomy and extended pelvic lymphadenectomy. BJU Int. 2011;107:220-5.

6. Antunes AA, Srougi M, Dall'Oglio MF, Crippa A, Nesrallah AJ, Nesrallah LJ,et al. Preoperative determination of prostate cancer tumor volume: analysis through biopsy fragments. Int Braz J Urol. 2007;33:477-83;discussion 484-5.

7. Antunes AA, Srougi M, Dall'Oglio MF, Crippa A, Campagnari JC, Leite KR. The percentage of positive biopsy cores as a predictor of disease recurrence in patients with prostate cancer treated with radical prostatectomy. BJU Int. 2005;96:1258-63.

8. D'Amico AV, Whittington R, Malkowicz SB, Schultz D, Fondurulia J, Chen MH, et al. Clinical utility of the percentage of positive prostate biopsies in defining biochemical outcome after radical prostatectomy for patients with clinically localized prostate cancer. J Clin Oncol. 2000;18:1164-72.

9. Freedland SJ, Aronson WJ, Terris MK, Kane CJ, Amling $\mathrm{CL}$, Dorey $\mathrm{F}$, et al. Percent of prostate needle biopsy cores with cancer is significant independent predictor of prostate specific antigen recurrence following radical prostatectomy: results from SEARCH database. J Urol.2003;169:2136-41.

10. Epstein Jl, Allsbrook WC Jr, Amin MB, Egevad LL; ISUP Grading Committee. The 2005 International Society of Urological Pathology (ISUP) Consensus Conference on Gleason Grading of Prostatic Carcinoma. Am J Surg Pathol. 2005;29:1228-42.

11. Kirkwood BR, Sterne JAC. Essential medical statistics. Massachusetts, Blackwell Science. 2006; 2a. pp. 502.

12. Hosmer DW, Lemeshow S. Applied Logistic Regression. New York, Wiley, 2000, 2a. pp. 320. 
13. Presti JC Jr, O’Dowd GJ, Miller MC, Mattu R, Veltri RW. Extended peripheral zone biopsy schemes increase cancer detection rates and minimize variance in prostate specific antigen and age related cancer rates: results of a community multi-practice study. J Urol. 2003;169:125-9.

14. Patel AR, Jones JS. Optimal biopsy strategies for the diagnosis and staging of prostate cancer. Curr Opin Urol. 2009;19:232-7.

15. Babaian RJ, Toi A, Kamoi K, Troncoso P, Sweet J, Evans R, et al. A comparative analysis of sextant and an extended 11-core multisite directed biopsy strategy. J Urol. 2000;163:152-7.

16. Eskew LA, Bare RL, McCullough DL. Systematic 5 region prostate biopsy is superior to sextant method for diagnosing carcinoma of the prostate. J Urol. 1997;157:199-202; discussion 202-3.

17. Nesrallah L, Nesrallah A, Antunes AA, Leite KR, Srougi M. The role of extended prostate biopsy on prostate cancer detection rate: a study performed on the bench. Int Braz J Urol. 2008;34:563-70; discussion 570-1.
18. Leite KR, Srougi M, Bevilacqua RG, Dall'Oglio M, Andreon C, Kaufmann JR, et al. Quantification of tumor extension in prostate biopsies - importance in the identification of confined tumors. Int Braz J Urol. 2003;29:497-501.

19. Engel J, Bastian PJ, Baur H, Beer V, Chaussy C, Gschwend $\mathrm{JE}$, et al. Survival benefit of radical prostatectomy in lymph node-positive patients with prostate cancer. Eur Urol. 2010;57:754-61. 